\title{
Clinical Characteristics of Nutritional Indicators in Patients with Covid-19
}

\author{
BO YUAN ZHANG, Y. T. SUN ${ }^{1}$, H. PAN ${ }^{2}$ AND LI ZHANG ${ }^{1 *}$ \\ Hebei University of Chinese Medicine, No. 3, Xingyuan Road, Shijiazhuang, Hebei 050200, ${ }^{1}$ Department of Respiratory Medi- \\ cine, ${ }^{2}$ Department of Orthopedics, Cangzhou Hospital Of Integrated TCM-WM, Hebei, No. 31, Huanghe West Road, Cangzhou, \\ Hebei 061001, China
}

\section{Zhang et al.: Characteristics of Nutritional Indicators in COVID-19 Patients}

\begin{abstract}
The purpose of this study was to retrospectively analyze the clinical significance of serum total protein, serum globulin, serum albumin and white globular ratio of patients with coronavirus disease 2019 upon admission. Enrolled 82 cases of coronavirus disease 2019 patients admitted to Wuhan Seventh Hospital, Hubei Province, including 34 cases of ordinary patients, 32 cases of severe patients, and 16 cases of critical patients. The age, gender, chronic underlying disease, total serum protein, serum globulin, serum albumin and white globular ratio in 3 groups were collected. The blood routine indicators of each group of patients were tested and analyzed, and the inflammation indicators $C$-reactive protein and procalcitonin on the 1st, 3rd and 7th $d$ of treatment were compared. The experimental results showed that compared with ordinary patients and severe patients, the nutritional loss of critically ill patients was obvious. In clinical treatment, the decrease of albumin should be paid close attention and corrected in time.
\end{abstract}

Key words: Coronavirus disease 2019, nutritional indicators, blood routine, inflammation level

At the beginning of 2020, a new type of coronavirus pneumonia broke out in Wuhan, China, which has been named Coronavirus disease 2019 (COVID-19) by the World Health Organization ${ }^{[1]}$. COVID-19 is susceptible to infection and has a strong epidemic in the population, therefore, the disease has been included in Class B infectious diseases as stipulated by the Law of the People's Republic of China on the prevention and control of infectious diseases, and preventive and control measures for Class A infectious diseases have been taken ${ }^{[2]}$. The World Health Organization announced on March 11 that COVID-19 had become a pandemic. At present, the epidemic situation in China has been basically controlled, but the situation abroad is still grim, and the pressure of imported cases has doubled $^{[3]}$. As of 10:00 am on July 24, 2020, China has accumulated 86500 confirmed cases, 4656 deaths and 2029 imported cases, the world has accumulated 15566 493 confirmed cases and 631810 deaths ${ }^{[4]}$.

According to the "New corona virus pneumonia diagnosis and treatment plan (Trial Seventh Edition)", COVID-19 is clinically divided into mild, ordinary, severe, and critical ${ }^{[5]}$. In the process of early clinical treatment, different syndromes were found to have different laboratory data. In this study, a correlation analysis was conducted on the impact of nutritional indicators in laboratory tests on the diseases of patients with pneumonia. We retrospectively collected 82 cases of COVID-19 patients admitted to the Seventh Hospital of Wuhan City, Hubei Province. Relevant data analysis of total protein, albumin, globulin, and white globule ratio was carried out in order to evaluate the effect of COVID-19 on the nutritional status of patients.

\section{MATERIALS AND METHODS}

\section{Data collection:}

82 patients who were treated in the Wuhan Seventh Hospital from January 25, 2020 to March 20, 2020, and were diagnosed as positive for COVID-19 by nucleic acid detection of throat swabs and other specimens, which met the diagnostic criteria of ordinary type of COVID-19. This study was approved by the Ethics Committee of the Cangzhou Hospital of Integrated Traditional Chinese and Western Medicine in Hubei Province (batch number: 2020006). Retrospective analysis was conducted using previous medical records, 
but during the epidemic period, patients in the Wuhan ward were unable to sign informed consent due to protection requirements, moreover, this protocol would not involve patient privacy, and the results of this study might provide scientific basis for the promotion of COVID-19, so informed consent was exempted after approval. The diagnostic criteria of patients were in line with the "New coronavirus pneumonia diagnosis and treatment plan (Trial Seventh Edition)". The collected cases were divided into mild, ordinary, severe, and critical according to the admission situation and diagnosis and treatment plan. Among them, ordinary type: fever, respiratory symptoms, etc., pneumonia could be seen under imaging; severe type: respiratory distress, blood oxygen saturation at rest was less than $93 \%$, and it is diagnosed as severe type if it meets at least one of the above points; critical type: respiratory failure, which needs mechanical ventilation, shock, combined with other organ failure, which is diagnosed as critical type.

\section{Research methodology:}

The study was a retrospective study. The patient's gender, age, underlying disease, and $24 \mathrm{~h}$ blood samples after admission were collected for laboratory tests, including: total protein, albumin, globulin, and white sphere ratio. XN-hematology analyzer was used to check the blood routine of each group of patients, and Hitachi 7600 biochemical analyzer was used to check the inflammatory factors C-reactive protein (CRP) and procalcitonin (PCT) of each group of patients. According to the diagnosis and treatment plan, the collected cases were divided into ordinary type, severe type, and critical type. Among them, there were 34 cases of ordinary type, 32 cases of severe type, and 16 cases of critical type. Compared the differences in nutritional indicators (total protein, albumin, globulin, white globular ratio) of the three groups of patients; performed routine blood tests (white blood cell (WBC), Neutrophils (NEUT), platelet count test (PLT), neutrophil to lymphocyte ratio (NLR), mean platelet volume (MPV), Lymphocytes (LYM), hemoglobin $(\mathrm{Hb})$ test, and platelet distribution width (PDW)) for each group of patients and compared the levels of inflammatory factors CRP and PCT on the $1^{\text {st }}, 3^{\text {rd }}$ and $7^{\text {th }} \mathrm{d}$ of treatment in each group.

\section{Statistical methods:}

Statistical package for the social sciences (SPSS) 23.0 statistics software was used for data analysis. All counting data are described in percentage. The measurement data are described by mean \pm standard deviation $(\mathrm{x} \pm \mathrm{s})$ by multivariate linear regression analysis, $\mathrm{p}<0.05$ was considered significantly different.

\section{RESULTS AND DISCUSSION}

Of the 82 patients with general condition, 34 were ordinary (median age $57.5 \mathrm{y}$ ), 32 were severe (median age $62 \mathrm{y}$ ) and 16 were critical (median age $65.5 \mathrm{y}$ ). Among the 82 patients, 38 patients were complicated with underlying diseases, as shown in Table 1.

The nutrient index decline was lower than the normal value and the specific expression was shown in Table 2. The total protein, albumin, globulin, and white globule

TABLE 1: COMPARISON OF GENERAL DATA OF EACH GROUP

\begin{tabular}{lccc}
\hline Group & $\begin{array}{c}\text { Ordinary } \\
(\mathrm{n}=34)\end{array}$ & $\begin{array}{c}\text { Severe } \\
(\mathrm{n}=32)\end{array}$ & $\begin{array}{c}\text { Critical } \\
(\mathrm{n}=16)\end{array}$ \\
\hline Age $(\mathrm{y})$ & & & \\
$\begin{array}{l}\text { Average } \\
\pm \text { standard }\end{array}$ & 60.41 & 60.16 & 59.25 \\
vertebra & \pm 12.948 & \pm 15.523 & \pm 19.814 \\
$\begin{array}{l}\text { Median } \\
\text { Gender }\end{array}$ & 61.5 & 58.5 & 64.5 \\
$\begin{array}{l}\text { Male } \\
\text { Female }\end{array}$ & 13 & 18 & 12 \\
$\begin{array}{l}\text { Basic diseases } \\
\text { Hypertension }\end{array}$ & 21 & 14 & 4 \\
$\begin{array}{l}\text { Diabetes } \\
\text { Coronary heart disease }\end{array}$ & 1 & 1 & 3 \\
$\begin{array}{l}\text { Cerebral } \\
\text { infarction }\end{array}$ & 1 & 10 & 7 \\
$\begin{array}{l}\text { Splenectomy } \\
\text { Uremia } \\
\text { Chronic obstructive }\end{array}$ & 1 & 1 & 1 \\
pulmonary disease & 0 & 1 & 2 \\
\hline & 0 & 1 & 1 \\
\hline
\end{tabular}

TABLE 2: DECLINE OF NUTRITIONAL INDEXES IN EACH GROUP

\begin{tabular}{llccc}
\hline Indicators & $\begin{array}{c}\text { Number } \\
\text { of cases }\end{array}$ & Normal & Decline \\
\hline \multirow{2}{*}{ Total } & Ordinary & 34 & $12(35.29 \%)$ & $22(64.71 \%)$ \\
protein & Severe & 32 & $10(31.25 \%)$ & $22(68.75 \%)$ \\
& Critical & 16 & $5(31.25 \%)$ & $11(68.75 \%)$ \\
& Ordinary & 34 & $9(26.47 \%)$ & $25(73.53 \%)$ \\
Albumin & Severe & 32 & $4(17.65 \%)$ & $28(82.35 \%)$ \\
& Critical & 16 & 0 & $16(100 \%)$ \\
\multirow{4}{*}{ Globulin } & Ordinary & 34 & $32(94.15 \%)$ & $2(5.88 \%)$ \\
& Severe & 32 & $30(93.75 \%)$ & $2(6.25 \%)$ \\
\multirow{4}{*}{ White } & Critical & 16 & $16(100 \%)$ & 0 \\
Ratio & Ordinary & 34 & $24(79.41 \%)$ & $7(20.59 \%)$ \\
& Severe & 32 & $22(68.75 \%)$ & $10(31.25 \%)$ \\
& Critical & 16 & $3(18.75 \%)$ & $13(81.25 \%)$ \\
\hline
\end{tabular}


ratios of the 3 groups of patients were statistically analyzed (Table 3 ). The results showed that the ratio of albumin, globulin, and white globules between the 3 groups was statistically significant, but the difference between total proteins was not statistically significant $(\mathrm{p}>0.05)$.

The WBC, NEUT, PLT, NLR and MPV of severe and critical patients were significantly higher than those of ordinary type $(\mathrm{p}<0.05)$, while the LYM, PLT, Hb and PDW of severe and critical patients were significantly lower than those of ordinary type $(p<0.05)$ (Table 4$)$.

The detection results of inflammation indexes at different stages of each group were shown in fig. 1, fig. 2, and fig. 3. After treatment, the CRP levels of patients in each group decreased significantly, and the differences were statistically significant $(p<0.05)$. The PCT decline was not significant, and the difference was not statistically significant ( $p>0.05)$; The PCT and CRP levels of severe and critically ill patients at all stages

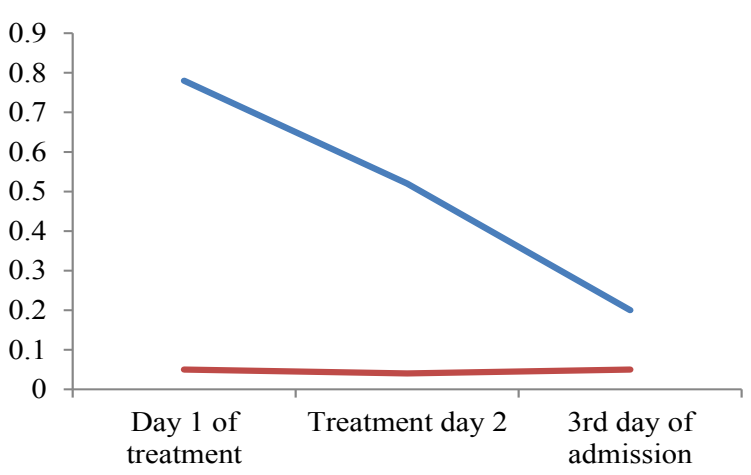

Fig. 1: Changes in levels of inflammatory factors in ordinary patients at different stages, ( $=$ CRP, ( were significantly higher than those of ordinary type $(\mathrm{p}<0.05)$.

The COVID-19 is caused by Severe acute respiratory syndrome coronavirus 2 (SARS-CoV-2) ${ }^{[6]}$. After comparison of virus sequences, the sequence identity between novel coronavirus 2019 (nCoV-2019) and a coronavirus in bats is as high as $96 \%$. It is speculated that the host of the virus may be wild animals such as bats, and there may be other intermediate hosts in the transmission from bats to humans ${ }^{[7]}$. The vast majority of patients are mild or ordinary, but some patients quickly develop severe or critical illness after the onset of disease ${ }^{[8]}$. COVID-19 is a viral infection, which is prone to poor immune function, increased basal metabolic rate and malnutrition ${ }^{[9]}$. It is a disease with extremely high infectiousness, high fatality rate and high disability rate. The main clinical manifestations of the patient are fever, dry cough, fatigue, nasal congestion and other symptoms ${ }^{[10]}$. Studies have shown ${ }^{[11]}$ that a small number of patients have no significant clinical

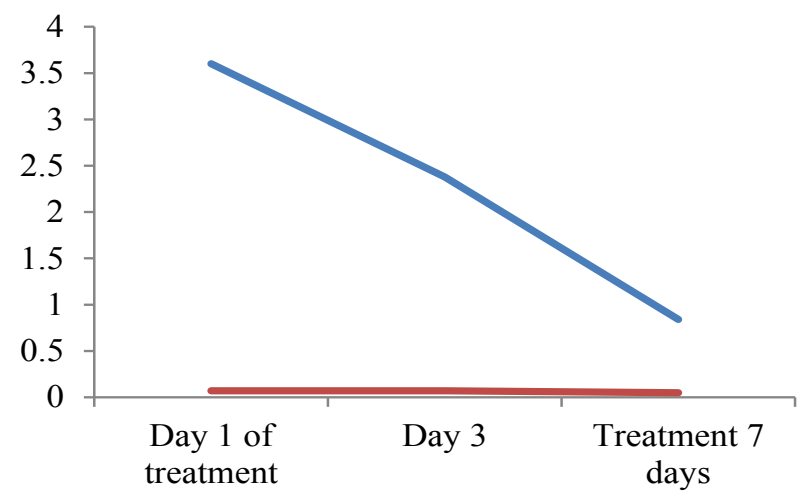

Fig. 2: Changes in levels of inflammatory factors in severe patients at different stages $(=)$ CRP, $(\rightleftharpoons)$ PCT

TABLE 3: CLINICAL TEST RESULTS OF NUTRITIONAL INDICATORS OF PATIENTS (x $\pm s)$

\begin{tabular}{lccccc}
\hline Group & Number of cases & TP of total protein & ALB of albumin & Globulin & White ratio \\
\hline Ordinary & 34 & $61.6 \pm 11.3$ & $37.0 \pm 4.5$ & $26.3 \pm 3.9$ & $1.44 \pm 0.32$ \\
Severe & 32 & $61.6 \pm 4.9$ & $34.6 \pm 5.2$ & $27.0 \pm 4.8$ & $1.33 \pm 0.37$ \\
Critical & 16 & $64.0 \pm 6.0$ & $32.0 \pm 4.2$ & $32.0 \pm 5.2$ & $1.04 \pm 0.25$ \\
F value & & 0.041 & 13.319 & 12.334 & 15.111 \\
p value & & 0.841 & 0 & 0.001 & 0 \\
\hline
\end{tabular}

TABLE 4: COMPARISON OF BLOOD ROUTINE INDEXES OF EACH GROUP

\begin{tabular}{lccc}
\hline Group & Ordinary $(\mathrm{n}=34)$ & Severe $(\mathrm{n}=32)$ & Critical $(\mathrm{n}=16)$ \\
\hline WBC $\left(\times 10^{9} \mathrm{l}\right)$ & $4.78 \pm 2.15$ & $5.14 \pm 1.03$ & $5.14 \pm 0.16$ \\
LYM $\left(\times 10^{9} \mathrm{l}\right)$ & $1.12 \pm 0.45$ & $0.95 \pm 0.14$ & $0.75 \pm 0.12$ \\
NEUT $\left(\times 10^{9} \mathrm{l}\right)$ & $3.01 \pm 0.15$ & $3.84 \pm 0.16$ & $3.83 \pm 0.15$ \\
PLT $\left(\times 10^{9} \mathrm{l}\right)$ & $187.45 \pm 23.15$ & $192.45 \pm 25.01$ & $122.45 \pm 26.23$ \\
NLR & $2.56 \pm 0.45$ & $4.62 \pm 0.15$ & $4.79 \pm 0.32$ \\
Hb (g/l) & $129.56 \pm 20.14$ & $126.45 \pm 21.03$ & $124.15 \pm 20.16$ \\
MPV (femtoliters (fl)) & $9.74 \pm 0.54$ & $9.61 \pm 1.02$ & $10.16 \pm 1.07$ \\
PDW (\%) & $15.74 \pm 2.01$ & $15.78 \pm 2.16$ & $13.26 \pm 1.04$ \\
\hline
\end{tabular}




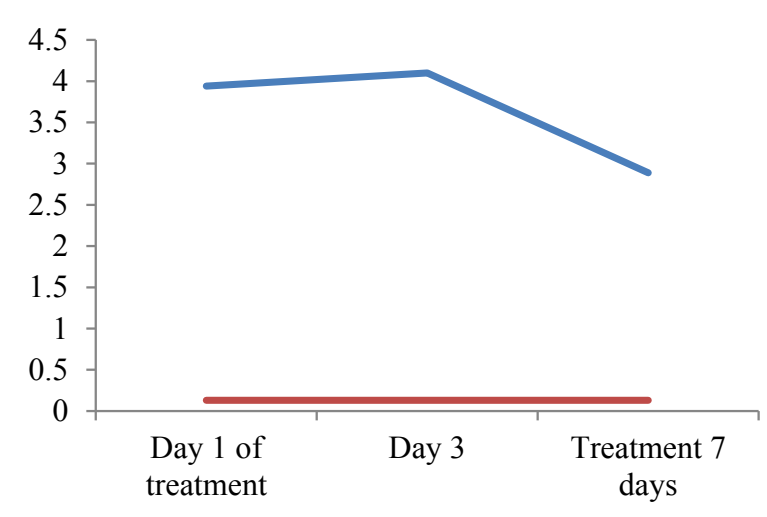

Fig. 3: Changes in levels of inflammatory factors in critical patients at different stages (

symptoms, which reduces the clinical diagnosis of patients, increases the transmission rate of this disease, and seriously threatens people's lives. COVID-19 has received widespread attention since its onset ${ }^{[12]}$. Zhong Nanshan et al. ${ }^{[13]}$ showed that the mortality rate of patients with COVID-19 infection is about $1.36 \%$, and the patients who need care in the intensive care unit account for about $5 \%$. This indicates that most patients with COVID-19 virus infection have a better prognosis, while the prognosis for severe and critically ill patients is poor. Therefore, the focus should be placed on critically ill patients during treatment ${ }^{[14]}$. Clinically, total protein, albumin, and globulin are often used in clinical nutritional assessment of patients. Therefore, this study is based on the analysis of the nutritional index data of 82 patients.

Serum total protein has many functions such as maintaining normal blood colloidal osmotic pressure and $\mathrm{pH}$, transporting a variety of metabolites, regulating the physiological effects of transported substances, and detoxifying their toxicity, immunity and nutrition ${ }^{[15-17]}$. Peng et $a l .{ }^{[18]}$ found that there were differences in nutritional status for different types of patients. In this study, a statistical analysis of total serum protein was first performed, and the results showed that it was not statistically significant $(\mathrm{p}>0.05)$. However, due to the small number of samples, whether total serum protein affects the severity of the disease or the number of people in the study needs to be further expanded. Serum total protein can be divided into two types: albumin and globulin. Statistical analysis of albumin and globulin respectively showed statistical significance $(p<0.05)$. The results showed: The more serious the clinical classification, the more obvious the decrease in albumin of patients. The reason for the decrease in serum albumin in COVID-19 patients is not clear, and it may be related to increased albumin catabolism (such as fever, stress), decreased synthesis or insufficient intake after viral infection. Globulin increased with the worsening of the disease, but basically fluctuated within the normal range (except for 2 cases of ordinary type and 2 cases of severe type, which were lower than normal). Serum globulin has the effect of enhancing the body's immunity and resisting infection. When the globulin is elevated, it is common in chronic inflammation and infection ${ }^{[19,20]}$. The white globule ratio is the result of albumin/globulin and we conducted a statistical analysis of the ratio, and the difference was statistically significant $(p<0.05)$. The more serious the disease, lower the white globule ratio, which indicated that the nutritional loss of patients is positively correlated with the severity of the disease. In the course of the research, it was found that the older and the more basic diseases are more likely to develop into severe and critical patients. This is consistent with the research results of Kofi Ayittey et al. ${ }^{[21]}$.

The above mentioned study examined the blood routine of patients and found that the WBC, NEUT, PLT, NLR and MPV of severe and critically ill patients were significantly higher than those of ordinary type, while the LYM, PLT, Hb and PDW of severe and critically ill patients were significantly lower than those of ordinary type. This indicated that the occurrence of anemia in severe and critically ill patients was more serious. This is consistent with the research results of Xiao et al. ${ }^{[22]}$. Umer et $a l .{ }^{[23]}$ found that the patient's inflammatory response deepened with the severity of the disease. The study by Atzrodt et al..$^{[24]}$ also showed that the level of inflammatory factors in critically ill patients was significantly higher than that in ordinary patients. We also found that the levels of inflammatory factors in severely ill and critically ill patients were significantly higher than those in ordinary patients, suggesting that as the degree of new coronavirus infection deepens, the severity of the inflammatory response in patients increases. This is consistent with the results of Lin et al. ${ }^{[25]}$.

\section{Acknowledgements:}

This work was supported by Hebei University of Chinese Medicine and Cangzhou Hospital of Integrated TCM-WM, Hebei.

\section{Conflict of interest:}

The authors declared no conflict of interest. 


\section{REFERENCES}

1. Phan T. Novel coronavirus: From discovery to clinical diagnostics. Infect Genet Evol 2020;79:104211.

2. Wang C, Horby PW, Hayden FG, Gao GF. A novel coronavirus outbreak of global health concern. Lancet 2020;395:470-3.

3. Xie M, Chen Q. Insight into 2019 novel coronavirus-An updated interim review and lessons from SARS-CoV and MERS-CoV. Int J Infect Dis 2020;94:119-24.

4. Han Y, Yang H. The transmission and diagnosis of 2019 novel coronavirus infection disease (COVID-19): a Chinese perspective. J Med Virol 2020;92:639-44.

5. Hong-Zhi DU, Xiao-Ying HO, Yu-Huan MI, Huang BS, DaHui LI. Traditional Chinese Medicine: an effective treatment for 2019 novel coronavirus pneumonia (NCP). Chin J Nat Med 2020;18:206-10.

6. Alizargar J. Risk of reactivation or reinfection of novel coronavirus (COVID-19). J Formos Med Assoc 2020;119:1123.

7. Tang AN, Tong ZD, Wang HL, Dai YX, Li KF, Liu JN, et al. Detection of novel coronavirus by RT-PCR in stool specimen from asymptomatic child, China. Emerg Infect Dis 2020;26:1337-9.

8. Yang H, Wang C, Poon LC. Novel coronavirus infection and pregnancy. Ultrasound Obstet Gynecol 2020;55:435-7.

9. Zhao J, Yuan Q, Wang H, Liu W, Liao X, Su Y, et al. Antibody responses to SARS-CoV-2 in patients with novel coronavirus disease 2019. Clin Infect Dis 2020;71:2027-34.

10. Paybast S, Emami A, Koosha M, Baghalha F. Novel coronavirus disease (COVID-19) and central nervous system complications: what neurologist need to know. Acta Neurol Taiwan 2020;29:24-31.

11. Jiang S, Xia S, Ying T, Lu L. A novel coronavirus (2019-nCoV) causing pneumonia-associated respiratory syndrome. Cell Mol Immunol 2020;17(5):554.

12. Lo YD, Chiu RW. Racing towards the development of diagnostics for a novel coronavirus (2019-nCoV). Clin Chem 2020;66:503-4.

13. Hosseini ES, Kashani NR, Nikzad H, Azadbakht J, Bafrani HH, Kashani HH. The novel coronavirus Disease-2019 (COVID-19): Mechanism of action, detection and recent therapeutic strategies. Virology 2020;551:1-9.

14. Garnier-Crussard A, Forestier E, Gilbert T, Krolak-Salmon P. Novel coronavirus (COVID-19) epidemic: What are the risks for older patients? J Am Geriatr Soc 2020;68:939-40.

15. Shajahan A, Supekar NT, Gleinich AS, Azadi P. Deducing the
$\mathrm{N}$-and $\mathrm{O}$-glycosylation profile of the spike protein of novel coronavirus SARS-CoV-2. Glycobiology 2020;30:981-8.

16. Buonsenso D, Piano A, Raffaelli F, Bonadia N, Donati KD, Franceschi F. Novel coronavirus disease-19 pnemoniae: a case report and potential applications during COVID-19 outbreak. Eur Rev Med Pharmacol Sci 2020;24:2776-80.

17. Willis MD, Robertson NP. Multiple sclerosis and the risk of infection: considerations in the threat of the novel coronavirus, COVID-19/SARS-CoV-2. J Neurol 2020;267:1567-9.

18. Peng Y, Zhou YH. Is novel coronavirus disease (COVID-19) transmitted through conjunctiva? J Med Virol 2020;92:1408-9.

19. Kim H. Outbreak of novel coronavirus (COVID-19): What is the role of radiologists? Eur Radiol 2020;30:3266-7.

20. Han Q, Lin Q, Ni Z, You L. Uncertainties about the transmission routes of 2019 novel coronavirus. Influenza Other Respir Viruses 2020;14:470-1.

21. Ayittey FK, Dzuvor C, Ayittey MK, Chiwero NB, Habib A. Updates on Wuhan 2019 novel coronavirus epidemic. J Med Virol 2020;92:403.

22. Xiao SY, Wu Y, Liu H. Evolving status of the 2019 novel coronavirus infection: Proposal of conventional serologic assays for disease diagnosis and infection monitoring. J Med Virol 2020;92:464-7.

23. Umer FA, Haji Z, Zafar KA. Role of respirators in controlling the spread of novel coronavirus (COVID-19) amongst dental healthcare providers: a review. Int Endod J 2020;53:1062-7.

24. Atzrodt CL, Maknojia I, McCarthy RD, Oldfield TM, Po J, Ta KT, et al. A Guide to COVID-19: a global pandemic caused by the novel coronavirus SARS-CoV-2. FEBS J 2020;287:363350.

25. Lin C, Ding Y, Xie B, Sun Z, Li X, Chen Z, et al. Asymptomatic novel coronavirus pneumonia patient outside Wuhan: the value of CT images in the course of the disease. Clin Imaging 2020;63:7-9.

This is an open access article distributed under the terms of the Creative Commons Attribution-NonCommercial-ShareAlike 3.0 License, which allows others to remix, tweak, and build upon the work non-commercially, as long as the author is credited and the new creations are licensed under the identical terms

This article was originally published in a special issue, "Evolutionary Strategies in Biomedical Research and Pharmaceutical Sciences" Indian J Pharm Sci 2020:83(3) Spl issue;57-61 